\title{
VICENT SALES
}

\author{
MAR VIOLETA ORTEGA-REIG \\ GUILLERMO PALAU SALVADOR ${ }^{\mathrm{c}}$
}

\section{GESTIÓN, TRANSFORMACIÓN Y DESAPARICIÓN DEL ARROZAL AL NORTE DE LA CIUDAD DE VALÈNCIA \\ (1767-1976)}

\begin{abstract}
RESUMEN
Hasta los años 70 del siglo XX, existieron espacios al Norte de la ciudad de Valencia con importantes zonas dedicadas al cultivo del arroz con una gestión de los recursos hídricos diferenciada claramente de las zonas de huerta, funcionando como territorios hidrosociales. El proceso de reubicación de las industrias de Valencia, la apertura de los nuevos accesos a la ciudad y el auge de la segunda residencia en la costa, contribuyeron a una rápida desaparición del arrozal.

PAlabras Clave: arrozal; gestión comunal; huerta; marjal; presión urbanística; territorio hidrosocial.
\end{abstract}

\section{Abstract}

\section{MANAGEMENT, TRANSFORMATION AND DISAPPEARANCE OF THE RICE FIELD NORTH OF THE CITY OF VALENCIA}

Until the 70s of the XXth century, there were spaces North of the city of Valencia with important areas dedicated to the cultivation of rice with a water resources management clearly differentiated

a President de la Fundació Assut. sequiola2000@gmail.com

b Investigadora, Centro Valenciano de Estudios Sobre el Riego, Universitat Politècnica de València

c Profesor Titular de Universidad. Universitat Poiltècnica de València, guipasal@agf.upv.es

Fecha de recepción: octubre 2018. Fecha de aceptación: abril 2019. 
from the orchard areas, functioning as hydrosocial territories. The process of relocation of the industries of Valencia, the opening of new entrances to the city and the boom of the second residence on the coast, contributed to a rapid disappearance of the rice fields.

Keywords: orchard; community management; hydrosocial territory; rice paddy; urban pressure; Wetland.

\section{INTRODUCCIÓN ${ }^{\mathrm{I}}$}

El cultivo del arroz en el País Valenciano se extiende sobre un conjunto de algo más de 15.000 hectáreas, localizadas, casi en su totalidad, dentro del ámbito del actual Parc Natural de l'Albufera, afectando a términos municipales de l'Horta Sud, la Ribera Baixa y el sur del término municipal de la ciudad de Valencia. Otros enclaves menores se localizan en la Ribera Alta, la Marina Alta y la Plana Baixa. La máxima ocupación en la provincia de Valencia debieron ser las casi 31.000 ha de los años veinte del pasado siglo. En 1952 la superficie ocupada por el arrozal se estimaba en algo más de 27.000 ha. La comparación entre las superficies de mediados del siglo XX y las dedicadas actualmente al cultivo nos indican, por una parte, la persistencia del cultivo en determinadas zonas: Ribera Baixa y Horta Sud-Valencia; y por otra, la práctica desaparición del cultivo en el resto de las comarcas valencianas. Han desaparecido los arrozales alejados de la costa (Ribera Alta, la Costera y la Canal de Navarrés), cuya inundación era artificial, aquellos espacios que Cavanilles denominaba "terrenos pantanosos por el arte" (Giménez, 2007, 298), permaneciendo parte de los cercanos a la costa, asentados sobre terrenos naturalmente pantanosos, sobre los que tan solo el cultivo arrocero era posible (Sanchis, 1978). También, por causas diversas, han desaparecido algunos otros, como los arrozales de la Safor, del Camp de Morvedre y de l'Horta Nord. Sobre estos últimos, sobre su origen, gestión del cultivo, utilización de los recursos hídricos, proceso de desaparición, y estado actual, centraremos nuestro trabajo. La acotación dentro de un marco temporal, 1767-1976, pretende fijar el tiempo, algo más de dos siglos, en que la actividad arrocera estuvo presente. El año 1767 aparece como la fecha del inicio de las plantaciones de arroz en la parroquia de Massamagrell (Massalfassar, Albuiex y los territorios de Rafalell y Vistavella) (Mateu, 1987, 41). El año 1976 es el año en que concluyó el proceso de reparcelación y adecuación de los arrozales de Puzol y su conversión en huertas por el Instituto Nacional de Reforma y Desarrollo Agrario (IRYDA). El arrozal requiere para su manejo de estrategias propias en el contexto del regadío tradicional del que participa pero con el que mantiene importantes diferencias, entre las que destacan una mayor necesidad de cooperación entre los actores y una dirección más centralizada Cabría entenderlos como territorios hidrosociales

1 Abreviaturas utilizadas en el texto: ARAM (Archivo de la Real Acequia de Moncada), AMMA (Archivo Municipal de Massamagrell), AMPF (Archivo Municipal de Pobla de Farnals), AMPU (Archivo Municipal de Puçol), AMALB (Archivo Municipal de Albuixec) 
(Swyngedouw, 1999, 2009) en los que la gestión del agua y la evolución del espacio físico están íntimamente ligadas a los procesos sociales y a la gestión política municipal. La compleja interacción de todos los factores socioeconómicos y biofísicos ligados a la gestión del agua de riego puede explicar los fenómenos de crecimiento, expansión y colapso de los sistemas a lo largo de la historia (Bjornlund y Bjornlund, 2019). La evolución de diferentes estados de la agricultura ha afectado a la gestión del agua de riego y la transformación de estos espacios. El sistema de riego tradicional de la RAM no escapa a estos procesos de modernización y antropización desde 1767 hasta 1976, aunque ciertas singularidades requieren un estudio pormenorizado de estos espacios.

El proceso de desaparición del arrozal al norte de la ciudad de Valencia y el subsiguiente cambio de uso de los espacios que ocupaba se produjo entre mediados de la década de los años sesenta y los años centrales de la de los setenta del siglo XX, además, con extrema rapidez. Las causas habrían sido diversas. Unas, relacionadas con la falta de rentabilidad del cultivo arrocero que llevó a su transformación en huertas como sucedió en Puçol, y otras ligadas a un desordenado proceso de urbanización consecuencia de la floreciente demanda de suelo destinado a construir segundas residencias y para asentar las industrias y servicios expulsadas de la ciudad. En ambas situaciones de cambio de uso del suelo, fue determinante la apertura del acceso norte por carretera a la ciudad de Valencia

\section{Los espacios Del ARROZAl EN L'Horta Nord}

La localización histórica de los arrozales al norte de la ciudad de Valencia presenta, históricamente, un doble asentamiento. Por una parte, en las huertas asociadas a los primeros tramos de la acequia de Moncada en el término de Paterna, por otra los localizados sobre la antigua albufera existente entre Puçol y Alboraia (Segura, 1995). Los primeros se asentaron sobre parcelas inundadas a voluntad con aguas de la acequia de Moncada; los segundos fueron beneficiados para el cultivo mediante actuaciones de drenaje para posibilitar el cultivo del arroz.

\subsection{El espacio físico de los regadíos al norte de la ciudad de Valencia.}

La presencia humana en los espacios situados al norte de la ciudad de $\mathrm{Valencia}^{2}$ consolidó un gran espacio regado -la huerta- que supuso una profunda antropización del medio natural. La geomorfología de esos espacios ha sido ampliamente descrita por Carmona (1990), Camarasa (1991) y Segura (1995); de forma más intuitiva lo había sido por Antonio José de Cavanilles (1795, 129-131) o José Rodrigo Pertagás (1922). La parte más significativa de esos espacios se corresponden con los irrigados por la Real Acequia de Moncada (RAM) que

2 Espacios que se corresponde con la actual comarca de l'Horta Nord. 
ocupan las terrazas de la margen izquierda del curso bajo del Turia, parte de la plana litoral entre el Turia y el barranco de Carraixet, y los espacios al norte de esta rambla y el margen sur del cono aluvial del río Palancia. En este último, en el antepaís de las playas, se localizaban una sucesión de formaciones lagunares, albuferas, hoy colmatadas y reducidas en su superficie por el aporte sedimentario y la acción antrópica. Tras los procesos de colmatación cuaternarios, las antiguas albuferas quedaron convertidas en espacios de marjal ${ }^{3}$ cuya anchura oscilaría entre uno y dos kilómetros (Segura, 1996, 64). La presencia de afloramientos de agua contribuía a dificultar su utilización como espacios agrícolas convencionales (Cavanilles, 1795). La cronología de los arrozales de la ribera del Turia (Paterna) se remontaría a época andalusí y continuaría en tiempos feudales como nos indican las ineficaces prohibiciones del cultivo del arroz promulgadas por los monarcas medievales tanto para la ciudad de Valencia (Pedro IV en 1342), como para todo el Reino (Martín I el Humano en 1403) (Giménez, 2008,273 ). La presencia del arroz en la huerta de Paterna prosiguió en el siglo XVI (Sales, 2011) hasta su definitiva prohibición en 1769 (Mateu, 1987, 40). Por su parte el origen de la expansión del cultivo del arroz a los espacios de la marjal al norte del barranco de Carraixet habría que situarlo en el territorio de la parroquia de Massamagrell (Massalfassar, Albuixec, Rafalell y Vistavella) en el año 1767 (Mateu, 1987, 41).

\subsection{El arrozal antiguo. Pantanos por el arte}

Los arrozales de las huertas de Paterna forman parte de un área mayor con los otros pueblos ribereños del río Turia (Villamarxant, Benaguasil, la Pobla de Valbona, Ribarroja y Manises), municipios que dedicaban partes importantes de sus huertas, como uno más, al cultivo del arroz. Los arrozales en las riberas del Turia habrían tenido su origen en época andalusí (Glick, 1988, 174.). En la Visura del canal de Moncada en 1576 (Sales, 2011) se pone de manifiesto la importancia del cultivo de arroces en la huerta de Paterna. Cavanilles $(1795,151)$ destaca la importancia del arroz dentro de las huertas de los términos que venimos citando, y se felicita por la prohibición del cultivo, vigente desde 1769. La descripción que hace Madoz (1848) no refleja la existencia de arrozales en Paterna para esas fechas y recalca la vigencia de la prohibición, en Villamarxant y Beneguacil. En 1886 (Anónimo, 1887), en los informes que se manejan con motivo de la Comisión creada para el estudio de la crisis arrocera, los municipios ribereños del río Turia no aparecen con espacios dedicados al arroz. En la relación de municipios donde se cultivan arroces en la provincia de Valencia (Carrasco, 1952, 421) no aparecen como tales ninguno de los municipios ribereños del Turia. Cabría pensar que, al menos legalmente, tras las prohibiciones de la segunda mitad del siglo XVIII el cultivo del arroz dejó de hacerse en las huertas de Paterna, dentro de la tendencia

3 Espacios de drenaje impedido que permanecen durante gran parte del año encharcados. 
general a circunscribir el cultivo del arroz a los terrenos inundados naturalmente, y abandonar el cultivo de los arrozales regados.

\subsection{El arrozal en los espacios litorales. La marjal}

A mediados de los años cincuenta del pasado siglo, en el imaginario colectivo de los huertanos al norte del Carraixet, la marjal era, un agro-espacio que, aunque próximo en la distancia, estaba lleno de peculiaridades que le otorgaban un halo mítico. Frente a las confortables huertas que rodeaban los pueblos, donde ninguna parcela queda lejos de un camino, y hasta la más minúscula de ellas dispone de su acequia para administrar el riego a voluntad; donde la variedad de cultivos y barbechos marcaban discontinuidades, la marjal aparecía como un continuo de aguas invernal. Desde los pueblos dos caminos partían atravesando las huertas. Uno hacia el oeste, el "camí del secà" que más allá del canal de Moncada, conducía a los campos resecos de algarrobos y olivares y los manchones verdes de huertos de naranjos ${ }^{4}$. Hacia el este el "camí de la mar" o "el camí de la marjal" que, curveando, bordeado de macizos de cañaverales cruza la vía de Campos ${ }^{5}$ para, de repente, abrirse sobre un continuo de verdes o de tierras o de aguas, según la estación. Un espacio donde todo es distinto, el cultivo, el manejo del agua, el parcelario, los nombres, incluso el comportamiento de los hombres.

\subsection{Jovedat versus Extremal}

El regadío de la acequia de Moncada cuenta con una antigüedad que se remonta a finales del s.X. El espacio potencialmente regable situado bajo la cota del canal, y hasta el Mediterráneo, abarca una gran superficie ${ }^{6}$ (Figura 1). El barranco de Carraixet disecciona el espacio regado de oeste a este dejando dos grandes espacios al norte y sur. Al sur, el límite meridional histórico lo establecía la yuxtaposición con los otros regadíos históricos (Tormos, Rascanya y Mestalla.) Al norte del Carraixet se distinguían los espacios más próximos al canal, denominados Jovedat que disfrutaba de plenos derechos al uso del agua del río Turia; y otros espacios denominados el Extremal que carecían de derechos plenos al agua, disfrutando, ocasionalmente, de los retornos de riego sobrantes de los espacios con pleno derecho, y también, aprovechándose de las aguas autóctonas mediante su afloramiento a través de fonts, ullals y cénies (Sales, 1988). Las cone-

4 Los secanos que se localizaban al oeste del canal de Moncada y se prolongaban sobre las vertientes al mediodía de la sierra Calderona, han sido dominio de los agricultores de la huerta, donde se plantaron algarrobos para alimentar las innumerables caballerías necesarias en los campos regados, y olivos para suministrar el tan necesario complemento dietético.

5 En el habla popular "la vía de Campos" hace referencia al ferrocarril Valencia-Tarragona. En realidad sería la "vía de Campo": José Campo Pérez, marqués de Campo (Valencia, 22 de mayo de 1814 - Madrid, 19 de agosto de 1889) fue el presidente de Sociedad de los Ferrocarriles de Almansa a Valencia y Tarragona.

6 La Comunidad de Regantes de la Real Acequia de Moncada proporcionaba riegos en el momento de mayor extensión de estos-1950 - a 76.386 hanegadas (6.365 hectáreas). 
xiones entre las redes de riego del Jovedat y las del Extremal presentan especificidades en cada término municipal, siendo, en ocasiones un continuo y, en otras, las menos, abruptas (Sales 2015, 382).

Unido a los proyectos de regularización de río Turia iniciados en los años treinta del siglo $\mathrm{XX}$, y concretados en las grandes obras hidráulicas de los años centrales del siglo, se produjo entre los regantes un cambio de percepción respecto de la sostenibilidad del sistema, vinculada al incremento en la seguridad en el abastecimiento de agua, fundamental en los meses primaverales y estivales. El río, con un régimen natural mediterráneo, con fuerte estiaje, tras la regulación podía garantizar los riegos estivales. La limitación histórica de los derechos a la utilización del agua, anteriormente de uso exclusivo para el Jovedat que había garantizado la sostenibilidad del sistema, dejó de tener importancia. A partir de la regulación, las aguas fluyentes serían de uso exclusivo por los regantes del Jovedat, en tanto que, las aguas reguladas serían compartidas en igualdad de derechos por las tierras de Extremal (Sales, 2015, 327 y sig.). Desde este momento todo el espacio localizado bajo la línea de rigidez del canal de Moncada pudo disfrutar de sus aguas, a la vez, que participar de los gastos de mantenimiento.

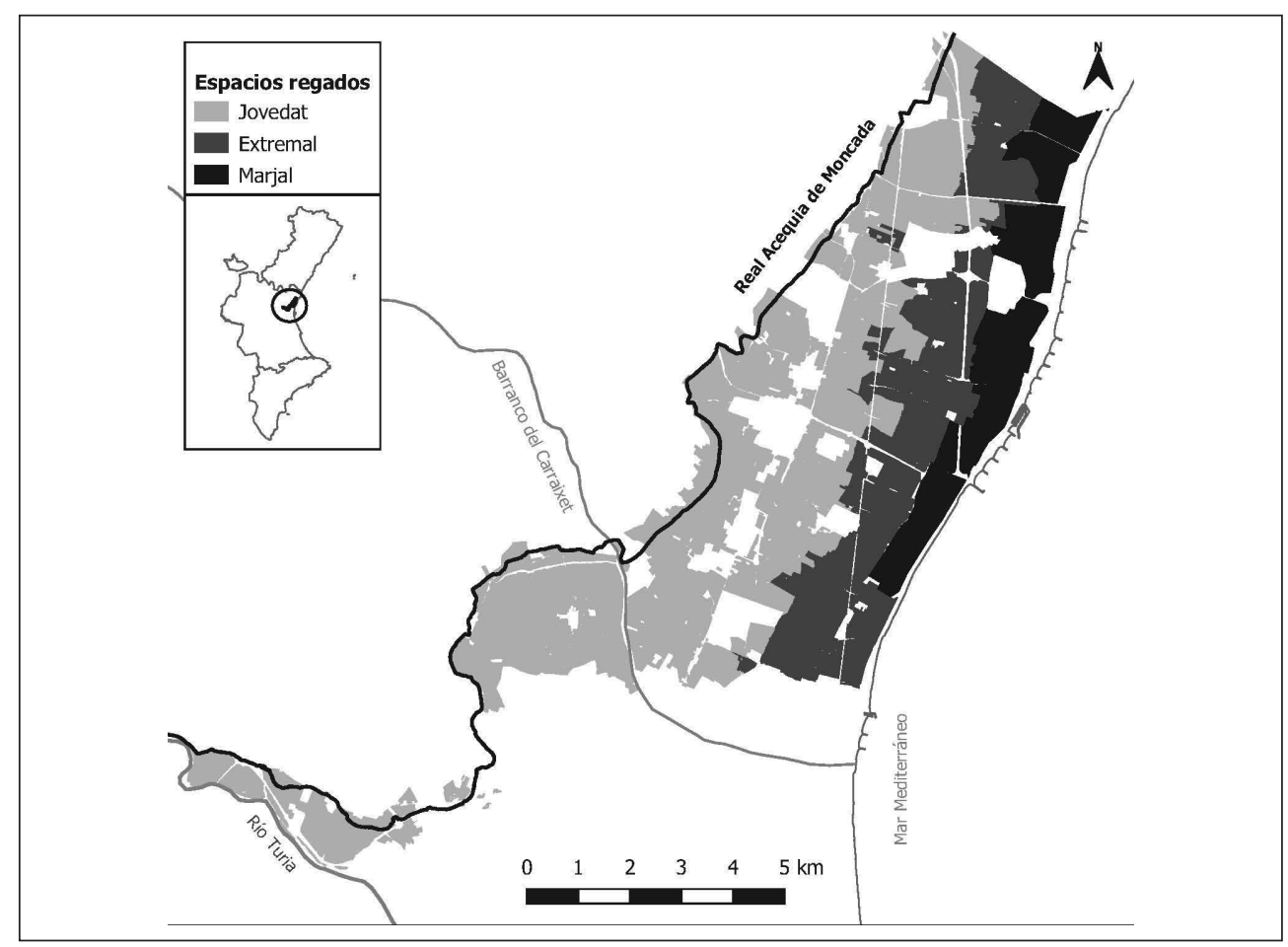

Figura 1. Espacios de Jovedat, Extremal y Marjal en la Real Acequia de Moncada. 
Organizativa e institucionalmente, el Jovedat había disfrutado históricamente de la solidez de la Comuna (estructura organizativa de la Comunidad de Regantes o la llamada Comuna de la Real Acequia de Moncada), configurada como una institución supramunicipal que administraba y regulaba todo el sistema de riegos proveniente del río Turia, y era dueña de la red de riego y de los artefactos que la regulaban. La Comuna tenía, y tiene, unas competencias que superan el marco municipal. En el Extremal la organización e institucionalización, cuando la tuvo, se dio a escala municipal, lo que permite considerar el Extremal como un agregado de espacios autónomos, desconectados, física e institucionalmente, al punto que podemos hablar de extremales de ámbito municipal: un Jovedat, y varios extremales?

\subsection{Extremales y marjales}

Dentro de estos espacios de Extremal coexistían dos grandes subespacios: 1) las huertas irrigadas, con una estructura en la red de riego, un parcelario y un uso agrícola históricamente similar al de las huertas históricas del Jovedat, con el que limitan por el oeste; y 2) las marjales, localizadas al este de las huertas del Jovedat y del Extremal, y entre ellas y el mar, extendidas por debajo de la cota de $3 \mathrm{msnm}$; espacios con suelos hidromorfos con el drenaje originalmente impedido, en los que se acumulaban las aguas procedentes de la escorrentía natural, las de los retornos de riego de las huertas, y las de los flujos hídricos provenientes de fonts y ullals y cenies (Sales, 2015, 204-225). La marjal poseía salidas al mar naturales o artificiales -les goles- ${ }^{-}$, a ellas iban a desembocar una laxa red de canales de drenaje denominados sequiols. El drenaje permitía el control de los niveles del agua y, en consecuencia, la parcelación y el aprovechamiento agrícola, concretado en el cultivo arrocero. La propia morfología del terreno, unida a la presencia de agua durante largos periodos, creaban un parcelario, y una red de acequias, que difería del típico de las zonas de huertas. La autonomía de riego que caracteriza al sistema general, en el que cada parcela puede ser regada independientemente de las contiguas, con una densidad muy elevada de canales, en la marjal se sustituye por un modelo de riego que implica la inundación casi permanente y sincrónica de grandes grupos parcelarios.

7 En Sales (2015, p.263-296) se hace una pormenorizada descripción de los distintos espacios de Extremal, de sus suministros hídricos de su localización, de su forma de gobernanza y de su relación institucional con la Comuna de la Real Acequia de Moncada.

8 Rossello Verger, V. (2003) define "gola" como "Obertura que comunica un riu, una albufera, etc., amb una massa d'aigua mes extensa. S'aplica especialment a la desembocadura d'un riu i a les obertures d'una restinga que comuniquen una albufera amb el mar". A lo largo de la costa, entre Albalat y el límite de Puçol con Sagunt se localizan hasta 10 golas de desagüe al mar. 


\section{El cultivo del arroz al norte de la ciudad de València9.}

El cultivo del arroz que se practicaba en la zona del estudio, hasta su desaparición definitiva, seguía los procedimientos tradicionales que implicaban el trasplante. El cultivo se iniciaba en unas parcelas preparadas al efecto y denominadas, "los planteles" que, tras de unos meses de cultivo, se trasplantaba a otras parcelas, el arrozal o marjal, donde completaba su ciclo vegetativo.

\subsection{El plantel}

El cultivo del arroz que se practicaba en las marjales de la zona de nuestro estudio, además de ser "inundado", comportaba el trasplante. El Reglamento para la ejecución de la real orden de 10 de mayo de 1860, relativa al acotamiento de terrenos con destino al cultivo del arroz (Anónimo,1887, 179), establecía las condiciones para autorizar los planteles. Solo se permitirían en terrenos acotados y que reuniesen determinadas características tales como: estar en las partidas más hondas y las más distantes de poblado en la dirección de los vientos dominantes. Los expedientes se instruían ante el ayuntamiento respectivo que se asesoraba de facultativos médicos y de peritos labradores expertos. La superficie acotada de plantel mantenía una relación con la acotada para el cultivo definitivo en el mismo término municipal. La proporción que se establecía era, aproximadamente, de 1:5 (una hanegada de plantel por cada cinco de arrozal) ${ }^{10}$.

En el cultivo tradicional, los planteles ocupaban parte de la superficie de las huertas regadas con las aguas de la acequia de Moncada. La preparación y desarrollo del cultivo ocupaba las parcelas desde octubre a mayo (Carrasco, 1952). Semanalmente había que renovar el agua, bien con la procedente de la tanda semanal de la acequia de Moncada o bien de aguas autóctonas (fonts, norias, motores). Generalmente, los ayuntamientos tomaban a su cargo la dirección de los riegos, sustituyendo la autonomía en las decisiones de los labradores, intrínseca al regadío, por un control centralizado que, como comprobaremos, acompañaba a la gestión del agua en el cultivo arrocero.

Las Actas del Ayuntamiento de Massamagrell entre finales del siglo XIX y primera mitad del XX nos han permitido reconstruir las acciones que desde el Ayuntamiento se dirigían al control hídrico de los planteles: nombrar regadores, gestionar los riegos con las aguas autóctonas, hacer cumplir el calendario de riegos, etc. La gestión del agua de riego del arrozal, ya en la primera fase del cultivo -el plantel- presuponía un tratamiento especial que implicaba

9 Sobre el cultivo del arroz con métodos tradicionales ver: Carrasco García, J.M. (1952, 176 y sig.); Rodríguez Navas, M (1906, 101 y sig.); García Montesoro, E. (1929); Anónimo (1926).

10 En ADPV. (1861-1862). C.3.2. caja 6, se hace una exhaustiva descripción de los líndes, extensión y localización de los planteles en el término municipal de El Puig 
una centralización de las decisiones del riego en manos de las municipalidades, en detrimento de la autonomía de los agricultores.

\subsection{La marjal. El arrozal}

La denominación arrozal no era la comúnmente utilizada para nombrar los espacios donde el cereal completaba su desarrollo. La denominación más utilizada era la de marjal, haciendo equivalentes el cultivo y el medio en que este prosperaba. Denominaciones referidas al municipio en que se localizaban, así se hablaba de marjal de Vistavella, de Albuixec, de Puçol, etc. Esta propensión localista hace pensar, al igual que en el caso de las huertas de Extremal, en una vinculación, especialmente en los aspectos hídricos, muy estrecha con cada uno de los municipios.

Los límites geográficos del arrozal litoral a mediados del siglo XX coincidían a grandes rasgos con los que asigna Segura (1996, p.66-67) a la albufera entre Puçol y Alboraia. Actuaciones antrópicas modernas la habrían ido reduciendo en su límite sur donde debió llegar hasta Meliana (Cavanilles, 1795, 138-139). A mediados del siglo XIX los arrozales de Albalat, Foios y Meliana habrían dejado de existir tras de las prohibiciones del siglo anterior (Madoz, 1848). Por el norte, el arrozal se prolongaba más allá de los espacios irrigados por la acequia de Moncada, adentrándose en el municipio de Sagunt. El límite este lo constituía la restinga ${ }^{11}$ de la antigua albufera. El límite oeste, donde el arrozal contacta con las huertas, tras de la creación de los cotos arroceros, de obligada construcción en cumplimiento de la Real Orden de 1753 dictada por Fernando VI (Giménez, 2007), cada municipio construyó azarbes de separación entre las huertas y los arrozales para impedir, en lo posible, el encharcamiento de las huertas. Estos azarbes, denominados salvadanys (salvadaños) eran imprescindibles para obtener la autorización del coto arrocero (Anónimo, 1887, 173).

La normativa general sobre los cotos arroceros se trasladó también a las ordenanzas municipales; como en las de Massamagrell de 1901'12. En Albuixec el azarbe aparece con el topónimo Acequia Nueva y circula paralelo al camino del Salvadany; en Massalfassar el límite es la acequia dels Salvadanys; en Massamagrell el límite entre huertas y arrozales los marcaba

11 Segura, Pardo y Sanjaume (1996, p.66): "La restinga tiene una longitud de 16 km y es bastante estrecha. Su anchura oscila entre 100 y $200 \mathrm{~m}$, excepto en aquellos tramos en los que se han acelerado los procesos erosivos costeros"

12 AMMA.Ordenanzas Municipales año 1901: "Art.486. Queda en absoluto prohibido la plantación y cría de arroces en terrenos no acotados legalmente. Los infractores quedan sujetos á las responsabilidades prescritas en la Ley y reglamentos sobre el cultivo del arroz. Art.487-= Asimismo queda prohibida la plantación de semilleros o planteles de arroz en terrenos legalmente no acotados" 
la acequia de Salvadaños. ${ }^{13}$ En la documentación consultada sobre Pobla de Farnals se han encontrado dos referencias al Salvadaños (Albadañs) ${ }^{14}$. Las Ordenanzas de la Comunidad de Regantes de las Tierras Arrozales de El Puig también, en su artículo $2^{\circ}$ introducen el término salvadaños. En Puçol el camí Nou y el azarbe que discurría paralelo a éste, perimetraban la amplia superficie de arrozales. Desde el azarbe partía un conjunto de canales, que se excavaron para drenar la marjal y conducir las aguas al mar en el que desaguaban por las golas. La escasa cota de la tierra firme favorecía la inundación de los espacios de la marjal. De forma recurrente, especialmente durante los fuertes temporales de levante, la circulación del agua se invertía y las aguas marinas penetraban por las golas inundando los arrozales; en Massalfassar la inundación con aguas marinas de parte de su marjal en $1947^{15}$. motivo que entre 1945 y $1952^{16}$ la RAM eximiera a esas tierras del pago del cequiaje. El descenso que se observa en la superficie del Extremal entre 1945 y 1952 se debe a la inundación (1947) por las aguas marinas de las parcelas más próximas al mar -todas ellas dedicadas al cultivo del arroz- que impulso a la Junta General de la RAM a dejar a esas parcelas exentas de pagar el cequiaje.

La red de canales que parten desde el salvadanys se estructuraba en unidades de drenaje independientes, con un canal principal -escurridor, sequiol- que unía el salvadanys con el mar y servía de colector principal de toda una red menor de acequias que desaguan en él. Entre el entramado que conforman los canales de primer orden y los de segundo, cuya imagen es la de un sistema fluvial típico, se destacan grandes conjuntos parcelarios cuyas parcelas no disponen de riego individualizado. La red de canales que sirve para drenar los espacios de marjal, sirve también para hacer llegar el agua a los conjuntos parcelarios del arrozal. El agua circula de unas parcelas a otras, fluyendo por aberturas hechas en los márgenes que sirven de linderos entre ellas. En los canales de riego-drenaje una serie de paradas (partidors) permitían dirigir el agua hacia cada conjunto parcelario, también mantener el agua en el interior de las parcelas a los niveles adecuados al estado del cultivo (Calatayud y Mateu, 1999, 263). El cultivo del arroz inundado, a lo largo de su ciclo de cinco meses en el terreno definitivo -de mayo a septiembre-, consume una importante cantidad de agua, $20.000 \mathrm{~m}^{3} /$ ha (Sales, 1986), gran parte de cual debe llegar a las parcelas de forma puntual y masiva, inundando el continuo parcelario dedicado al cultivo en los cotos arroceros. En el transcurso de muy

13 AMMA. 1903. Acta de Pleno de 1 de marzo de 1903.: "a propuesta de la Comisión de Fomento se acordó: Que por los propietarios colonos o cultivadores de cualquiera clase de fincas rústicas sea cuales fuera el cultivo a que se hallan destinadas, cuyo riego verifiquen en aguas de fuentes o manantiales comprendidos desde la Acequia de Salvadaños hasta el Mar, se proceda durante la semana entrante a la monda o limpia de cuantas acequias madres, brazales y escorredores utilicen para tal riego debiendo sacar el barro....."

14 AMPF. Libro n ${ }^{\circ} 14,1957-59 /$ Libro n $^{\circ} 12$ 1954-55.

15 Ibíd. Libro Anuario de 1947. Acta de Junta de 4 de julio de 1947.

16 ARAM. Libro Anuario de 1952. Acta de Junta de 31 de diciembre de 1952: "Se da lectura a un oficio del Ayuntamiento de Masalfasar, en el que dice que se reduzca su cabida de Extremales a 2.558 hanegadas que es la que verdaderamente tiene. La Junta acuerda que así se haga en el repartimiento del año entrante". 
pocas fechas L'omplida de les marjals (la inundación de las marjales), la plantà de l'arros (el trasplante y planación), l'aixugó (el secado), la segà de l'arros (la siega), constituían eventos puntuales a lo largo del año agrícola de especial relevancia. Labores de cultivo, especialmente las relacionadas con la gestión del agua, que no permiten un excesivo grado de autonomía y de decisión al agricultor. En cada conjunto parcelario, y en el conjunto del arrozal, labores como la inundación requieren de un alto grado de especialización en el personal que las ejecutan; requieren también sincronización; necesitan por tanto de una dirección centralizada $y$, en consecuencia, de instituciones con el suficiente respaldo comunitario como para poder imponer los intereses generales a los individuales. Por ello, el cultivo de arroz en estos territorios hidro-sociales es inseparable de los elementos que explican la gobernanza y gestión centralizada del cultivo de arroz.

La Comuna de Moncada podría haber sido la institución con el suficiente respaldo para imponer normas y tiempos en el manejo del agua del arrozal. Pero los espacios dedicados a este cultivo estaban fuera del control de la Comuna, eran en su totalidad extremales. La acción de la Comuna nunca fue más allá de atender, cuando pudo, los requerimientos para suministrar, en momentos puntuales -la inundación inicial y el agua nueva tras del eixugó-, agua para los arrozales localizados en el interior de su espacio regable. La gestión de los arrozales, incluso más allá de la gestión del agua, residió en los ayuntamientos que actuaban como gestores integrales del complejo sistema arrocero, cuya gestión abarcaba: el mantenimiento de la red de canales (mondas, limpiezas, construcción y mantenimiento de partidores), de los caminos, la gestión integral del agua, las pautas de cultivo (plantación, escardas, siega); a lo que se añadiría la gestión económica (elaboración de repartos, cobro de los cánones, contratación de personal especializado -regadores, guardas-, contratación de personal para limpieza de canales y golas, etc.) (Sales, 2015, 308).

La presión de las Hermandades Sindicales de Labradores y Ganaderos (HSLG) formadas por grupos afines a Falange Española (d'Amaro, 2014) sobre los ayuntamientos a finales de la década de los años 40 del siglo XX, propició el traspaso de la administración de las marjales a estas instituciones en algunos municipios: Puçol en $1952^{17}$, para dos años después recuperarla,

17 AMPU. Libro de Actas de 1952. Acta del 12 de agosto de 1952: "A continuación por el Secretario de orden del Sr. Presidente se dio lectura del escrito de la Hermandad Sindical de Labradores y Ganaderos de esta población, en el que reitera la petición hecha anteriormente, para que este Ayuntamiento, transfiera a dicha Hermandad la administración de la Marjal de este término. La Corporación tras breve discusión y por unanimidad acuerda, se transfiera a la Hermandad Sindical de Labradores y Ganaderos de esta, la administración de la Marjal". 
Albuixec ${ }^{18}$ en 1958, aunque no siempre con total aquiescencia ${ }^{19}$; en tanto que en otros -Massamagrell- el ayuntamiento se reservó la administración; en El Puig, desde 1888, la gestión de las tierras arrozales estuvo, aun lo está, en manos de una comunidad de regantes -Comunidad de Regantes de las Tierras Arrozales de El Puig- constituida exprofeso (Sales, 2015, 310)

\subsection{Los recursos hídricos del arrozal.}

El canal de Moncada, en su tramo al norte del barranco de Carraixet, ha venido actuando, salvo situaciones excepcionales, como un importante obstáculo a los flujos concentrados de agua que pudiesen llegar a la huerta desde los piedemontes contiguos y que no estuviesen vehiculados por el barranco de Carraixet y el de la Calderona. Una parte de la alimentación hídrica de las marjales litorales estuvo modificada desde la construcción del canal. Podríamos considerar que, desde la existencia del canal de Moncada, desde época islámica, el estado "natural" del espacio bajo su cota y hasta el mar, fue profundamente modificado, y las marjales litorales no fueron una excepción. El proceso de construcción de la huerta (Sales, 2015), culminó con la construcción del espacio agrario próximo al litoral, en el que los papeles estaban, en cierta forma, invertidos. En tanto que las huertas habían necesitado de una red de canales, el canal principal incluido, posibilitar la llegada del agua y la irrigación, los espacios de la marjal iban a necesitar una red de canales de drenaje que permitiesen el control de los niveles del agua y, en último término, posibilitasen la salida al mar de los sobrantes de todo el sistema. El arrozal se sitúa en la cola de todo el sistema de riegos de la acequia de Moncada y receptor de todos los posibles retornos. Además, la superficialidad del manto freático permitía que aflorara en la superficie del terreno. Retornos y afloramientos provocaban excesos hídricos. Los afloramientos hubo que controlarlos para crear un parcelario que a lo largo de ciertas épocas del año debería permanecer seco y permitir una parte de las labores de cultivo. Los retornos hubo que reconducirlos para ser utilizados de una forma distinta a cómo lo eran en las huertas limítrofes.

El arrozal más moderno e intensivo del siglo XX necesitó, como sucedió en las huertas de extremales, agudizar el ingenio para procurarse recursos hídricos suficientes para el cultivo. La conversión de las viejas cenias en motores de elevación de agua, o su excavación y equipamiento exnovo para surtir al arrozal se hizo común a todos los términos con marjal a partir de los años treinta. Albuixec, cuya Junta de Riegos no consideró la perforación de pozos ex-

18 Ibíd. Libro de Actas de 1954. Acta del 21 de enero de 1954.

19 La Junta General de la RAM había hecho saber al ayuntamiento de Puçol su oposición al traspaso de competencias a la HSLG. AMPU. Actas de pleno de 1952. Acta de 12 de agosto de 1952: "A este respecto, el Secretario informa, que en virtud del escrito de la Junta de Gobierno de la RAM n ${ }^{\circ} 45$ de fecha 3 de junio de 1952 que dice:

En contestación a su atento escrito de fecha 3 de Mayo último, $n^{\circ}$ 556, tengo el honor de comunicar a Vd. que esta Comunidad no presta su asentimiento a que las aguas de la misma en ese término municipal sean administradas por organismo distinto a ese Ayuntamiento...." 
profeso, compraba el suministro de agua de pozo para la marjal20 (Sales, 2015); Massamagrell excavó y equipo un pozo en 1945²1; Pobla de Farnals recurrió en 1939 a la compra de agua a diversos pozos del municipio ${ }^{22}$; en El Puig, la Comunidad de Regantes de las Tierras Arrozales de El Puig dispuso de varios pozos; en Puzol, la Asamblea de Propietarios de la Marjal, a partir de 1943, adquirió y construyó diversos pozos ${ }^{23}$. La importancia que para las economías familiares suponía el cultivo del arroz priorizó el uso de los recursos hídricos dedicados para el arrozal. En los tiempos en que no existió regulación del río Turia, las huertas estivales eran, las más de las veces, mantenidas en barbecho -guarets-, lo que debió permitir que, aunque careciendo de derechos, los arrozales se beneficiaran durante la época estival de las aguas de la acequia de Moncada. La práctica de la retancà- que consistía en dirigir durante un periodo corto de tiempo, un día o dos días, toda el agua que vehiculaba el canal de Moncada a la exclusiva inundación de los espacios dedicados al cultivo del arroz; solo de esa manera se pueden conseguir los volúmenes de agua suficientes para proceder a la inundación total de la superficie dedicada al arrozal. Hay que considerar que para efectuar la siembra o trasplante y elevar la lámina de agua a $12,5 \mathrm{~cm}$ deben estar en el momento inicial de llenado de la marjal presentes, al menos, $1.250 \mathrm{~m}^{3} / \mathrm{ha}^{24}$ y ese caudal se debe aportar en las primeras 24 horas, resultando que para regar una superficie por ejemplo de 300 ha (asimilable a las superficies de los arrozales de El Puig o de Puçol) se requiere un caudal constante de aproximadamente $4,34 \mathrm{~m}^{3} / \mathrm{seg}$ (durante 24 horas) y teniendo en cuenta que el canal principal de la acequia de Moncada puede vehicular un caudal máximo de $6 \mathrm{~m}^{3} / \mathrm{s}$, parece difícil imaginar otra forma de suplir las necesidades hídricas de l'omplida que no sea con el recurso a la retancà.

\subsection{La importancia del arrozal al norte de la ciudad de Valencia}

La importancia del cultivo del arroz en la economía comarcal queda puesta de manifiesto por el esfuerzo de gestión llevado a cabo por las instituciones públicas, especialmente los ayuntamientos; estos asumieron responsabilidades más allá de la lógica de un sistema agrario. Un férreo control público de la actividad privada en un contexto agrícola donde la autonomía y el individualismo eran la norma. Los ayuntamientos realizaron un control de la gestión hídrica e incluso de cuestiones nimias relacionadas con el cultivo del cereal. Una parte importante de los agricultores y propietarios de los espacios que estudiamos, compaginaban el cultivo de las huertas con el cultivo del arrozal. En las huertas regadas por la acequia de Moncada un sistema de "organización social", donde la comuna realizaba un

20 AMALB. Libro n5. De 1944 a 1945. Acta del 5 de septiembre de 1944.

21 AMMA. Acta de Pleno del 28 de agosto de 1945.

22 AMPF. Libro n³. 1939-1940. Acta del 1 de Octubre de 1939.

23 AMPU. Libro de Actas de 1943. Acta del 20 de mayo de 1943. Libro de Actas de 1946. Acta del 14 de febrero de 1946. Libro de Actas de 1952. Acta del 12 de agosto de 1952.

24 Por la conversión de unidades $12,5 \mathrm{~cm}$ equivalen a $125 \mathrm{~mm}$ de columna de agua y a $1250 \mathrm{~m}^{3} / \mathrm{ha}$. 
control supramunicipal de los recursos hídricos y donde el control de unos a otros ralentizaba la conflictividad, y donde la autonomía de las decisiones de los agricultores -respecto al qué plantar y al cómo cultivar- era básica, contrastaba con un arrozal donde el control externo era omnipresente. En las huertas, la acumulación de trabajo familiar podía, en determinadas situaciones, ayudar a superar diferencias debidas al tamaño de la explotación. En el arrozal, como ocurre generalmente en las economías agrarias de base cerealista, la mayor o menor superficie poseída determina las rentas.

A partir de 1860 (tabla 1) disponemos de datos sobre las superficies que en los términos arroceros se dedicaban al cultivo ${ }^{25}$. En 1952 la superficie dedicada a arrozal dentro del regadío de la RAM suponía aproximadamente el 15\% del total (10.500 de 76.368 hg); si nos referimos al regadío de la RAM al norte del Carraixet (un total de $61.257 \mathrm{hg}$ ) la superficie de arrozal era el 17\%. Si lo referenciamos al espacio de Extremal (un total de $30.443 \mathrm{hg}$ ) el arrozal ocupaba aproximadamente el 35\% de la superficie. Además, una parte importante de las huertas de estos municipios estaban durante, al menos, tres meses dedicadas al cultivo de planteles de $\operatorname{arroz}{ }^{26}$.

Tabla 1. Evolución histórica de los espacios dedicados al cultivo arrocero 1860-1952 (hanegadas)

\begin{tabular}{|l|l|l|l|l|}
\hline \multicolumn{1}{|c|}{ Pueblo } & \multicolumn{1}{|c|}{$1860 *$} & \multicolumn{1}{|c|}{$1886 * *$} & $1929 * * * *$ & $1952 * * * * *$ \\
\hline & & & & \\
\hline Vara de la calle de Morvedre*** & 898 & 898 & 898 & 898 \\
\hline Albuixec & 1459 & 1284 & 1800 & 1299 \\
\hline Massalfassar & 724 & 554 & & 738 \\
\hline Massamagrell & 205 & 163 & & 303 \\
\hline Pobla de Farnals & 479 & 537 & & 606 \\
\hline El Puig & 2299 & 2309 & 4272 & 4435 \\
\hline Puçol & 2152 & 2299 & 2928 & 2271 \\
\hline Total & 8216 & 8044 & 7200 & 10550 \\
\hline $\begin{array}{l}\text { *1860 Estado demostrativo de la producción media del arroz en la provincia de Valencia. } \\
\text { **1886 Copia de la relación de los distritos municipales que tributan por el cultivo del arroz. } \\
\text { ***Pedanías de Rafalell y Vistavella } \\
\text { ****García Montesoro (1929) } \\
* * * * * \text { Ministerio de Agricultura (1952) }\end{array}$ & & \\
\hline
\end{tabular}

25 No disponemos de datos concretos de las pedanías de Rafalell y Vistavella que deberían aparecer en el cómputo del término de la ciudad de Valencia, no obstante, atribuimos, para 1860, la superficie asignada a la Vara de la calle de Sagunto del término de la ciudad de Valencia a las pedanías citadas.

26 Es difícil precisar la superficie de planteles puesto que el rendimiento superficial varió mucho gracias a la aportación de abonos químicos nitrogenados (sulfato de amoniaco) pero debieron oscilar entre 700 y 1.500 hanegadas. 


\subsection{Historia de una desaparición anunciada}

"En 1966 fue abierta la actual avenida de Catalunya (acceso a Barcelona), con doble calzada, para convertirse en autopista, con cuatro vías, en 1972" (Teixidor, 1980, 163). Fue el principio del fin. Un secular paisaje, cuya resiliencia se había puesto a prueba durante centurias, no lo pudo superar. Mario Gaviria ${ }^{27}$ anunciaba en 1974 los graves destrozos que la autopista del Mediterráneo estaba ya causando sobre los espacios de agricultura de regadío intensivo de la huerta de Valencia. Todo sucedió con gran rapidez.

El 25 de febrero de 1966 el Pleno del ayuntamiento de la Pobla de Farnals ${ }^{28}$ tomó el acuerdo $^{29}$ de prohibir el cultivo del arroz debido a las dificultades de convivencia con la actividad urbanística. Los intereses de los constructores fueron decisivos para la supresión del arrozal. En Albuixec, el Pleno del Ayuntamiento de 13 de julio de 1971. El 13 de julio de 1971 el Pleno del ayuntamiento de Albuixec procedió a declarar el cambio de uso de sus arrozales declarándolos zona industrial para posibilitar su expropiación y conversión en el Polígono Industrial del Mediterráneo ${ }^{30}$.

En el Puig el proceso de desaparición del arrozal se ralentizó. A finales de los años 60 ya se había iniciado un desordenado cambio en el uso del suelo del arrozal con la construcción, junto al camino del Mar y en el centro del espacio dedicado al arrozal, de una gran planta industrial dedicada a la producción de cerveza -Cervecera del Norte-, construida y puesta en funcionamiento (1967) dentro de un contexto absolutamente agrícola y carente de cualquier tipo de infraestructura vial y de control de vertidos ${ }^{31}$. El arroz fue cediendo espacios a la construcción de residencias veraniegas en los espacios más próximos a la costa y a un gran núcleo industrial y servicios en el centro del espacio del arrozal; en 1972 la evidencia del cambio que se estaba produciendo ya era alarmante ${ }^{32}$ y se hacía necesaria una reordenación del espacio de la marjal

27 Un visionario y premonitorio artículo en el semanario TRIUNFO de 7 de marzo de 1974: "La autopista del Mediterráneo es un caso especialmente claro de lo dicho más arriba. Como se buscaban peajes de corto recorrido, el trazado de esta autopista va por las zonas densamente pobladas, pegándose a los cascos urbanos y por sectores que tienen una más larga tradición de agricultura intensiva, lo que va a significar un grave destrozo para la huerta de Valencia, por ejemplo."

28 ARAM. Libro anuario de 1967. Acta de Junta de 4 de diciembre de 1967: "Se da lectura a un oficio del Ayuntamiento de Puebla de Farnals, nuestro n ${ }^{\circ} 259$, de fecha 8 de noviembre último, en el que solicita la baja de 712 hanegadas de tierras Extremales por haber dejado de cultivarse al estar comprendidas dentro del Plan de Ordenación de la Playa de Puebla de Farnals"

29 AMPF. Libro nº 18. 1965-1966. Acta del 25 de febrero de 1966.

30 AMALB. Libro n 14. 1970-1975. Acta de Pleno de 13 de julio de 1971.

31 Ibíd. Doc. n 7. Actas de Pleno 1972-1977. Acta del 12 de agosto de 1975: "Visto el estado deplorable en que se encuentra el desagüe de las aguas residuales de la industria "Cervecera del Norte" instalada al lado del camino del Mar en este Término Municipal, cuyas aguas desde que funciona dicha industria vierten a una acequia general de riego de arrozales y desagüe al mar, vista la falta de interés por parte de esta empresa para corregir estas anomalías".

32 Ibíd. Doc. no 7. Actas de Pleno 1972-1977. Acta del 24 de febrero de 1972. 
En Puçol a mitad de la década de los años $60^{33}$, se inició un proceso de concentración parcelaria que afectó a los polígonos catastrales 9 y 10 -coincidentes con la marjal y zona del cultivo del arroz- que concluyó en 1976 año en que las obras de "caminos y transformación en regadío, pasos sobre acequias y pasos sobre desagües" fue entregada al Grupo Sindical $\mathrm{n}^{\circ} 16.099$ de Puçol, hoy SAT no 3.517 la Marjal. El sistema de irrigación cambió de forma radical. Un doble sistema de canales: de riego y avenamiento, con una estación de bombeo situada en la cola del sistema que eleva el agua al sistema de riego y permite la recirculación de las aguas para de nuevo ser aprovechadas para el riego. Se transformo el arrozal en huerta, construyendo de nueva planta una huerta con todas las características propias de esta: riego individualizado, que permitiera una variedad de cultivos y la posibilidad de tomar decisiones autónomas par parte de los agricultores.

El arrozal de Massamagrell y sus agregados Rafalell y Vistavella pervivieron algún tiempo hasta los inicios de los años 70 cuando se sustituyó el arroz por cultivos hortícolas y frutales. El cambio de uso del suelo en el caso de Massamagrell que calificó los espacios costeros como urbanos, y sucesivas operaciones especulativas sobre Rafalell y Vistavella han determinado el abandono de la actividad agrícola en todos estos parajes. En la actualidad existen sobre todo el conjunto -Massamagrell y las pedanías de Rafalell y Vistavella- figuras de protección ambiental.

En el trasfondo del proceso de profundo cambio que los espacios del arrozal experimentaron desde mediados de la década de los años 60 del siglo XX se encuentran la acción que sobre esos espacios han tenido las infraestructuras viarias. Antes de esas fechas, la comunicación de la marjal con los núcleos urbanos de los términos en que estaban incluidos, era penosa. Curveantes y polvorientos, caminos que unían los cascos urbanos con las playas, y unas escasas vías -els camins travessers- de enlace entre los distintos camins de la Mar, dibujaban una red caminera de utilidad exclusivamente local y agrícola. Desde 1862 los arrozales estaban cruzados por una casi invisible infraestructura ferroviaria: "el Ferrocarril del Grao a las Canteras de El Puig" que, por su propia funcionalidad, ejerció poca incidencia, paisajística y económica, sobre el espacio que atravesaba. Será la apertura de la Autovía de Acceso Norte Valencia a finales de los años 60 y principios de los 70, la infraestructura que tendrá una mayor incidencia en la transformación del paisaje. Construida sobre el trazado del Ferrocarril de las Canteras, más allá de los terrenos ocupados para su construcción ${ }^{34}$, la autovía propició

33 AMPU. HSLG. Actas. Acta del 2 de marzo de 1964.

34 ARAM. Libro Anuario de 1965. Acta de Junta de 16 de julio de 1965: "Con fecha 30 de diciembre de 1964, el Sr. Síndico de Puzol cursó un oficio comunicando la baja en cequiaje de 139 h y 3 cuartones por edificación y por ocupación de la nueva pista". Libro Anuario de 1964. Acta de Junta del 10 de octubre de 1964: "Se da lectura a un oficio del Ayuntamiento de Albuixech al que se adjunta un croquis de la zona a que se refiere y solicita la baja de noventa (90) hanegadas de Extremales con efectos a partir del año actual, por haber sido expropiadas por el Estado para la construcción de la nueva autopista de la costa". Libro Anuario de 1964. Acta de Junta del 31de diciembre de 1964:"Extremales de Masalfasar: Queda reducida su cabida contributiva a 2485 hanegadas, de acuerdo a lo solicitado por el Ayuntamiento, por haberse destinado el exceso a la autopista de de la costa" 
el cambio de uso del suelo en la medida en que posibilitó una acceso rápido y cómodo a los espacios de la marjal. La mejora de la accesibilidad propició la puesta en valor de esos espacios y los abrió a un acelerado cambio de uso.

\section{Discusión}

La construcción de un espacio agrícola sobre un territorio (no propicio), la marjal, había sido el resultado de un esfuerzo colectivo, obra de los agricultores y de su capacidad de organización. Con un estrecho tutelaje por parte de los ayuntamientos de los distintos municipios arroceros. El cultivo arrocero requirió unos modelos organizativos propios y distintos a los de las huertas contiguas cultivadas por los mismos agricultores. El control del agua, tanto en sus excesos, como de su necesidad, para el cultivo del arroz, generó formas organizativas propias forzadas por la peculiaridad del cultivo arrocero. La combinación de unos condicionantes bio-físicos que por una parte habían sido modificados y, por otra, aprovechados, generaron un marco agrario propicio para el desarrollo de un cultivo de gran influencia en la vida agrícola comarcal durante un dilatado espacio de tiempo. La rápida desaparición del cultivo arrocero y el cambio de uso del suelo se contextualiza dentro del proceso de aceleración global que, tanto en el marco regional como estatal, venía produciéndose a finales de la década de los años sesenta del siglo XX y que es acorde con el análisis global de los espacios irrigados que presentan Bjornlund y Bjornlund (2019).

Unos espacios resilientes, que reaparecían tras de los temporales de invierno que introducían aguas marinas o tras de las inundaciones provocadas por el Carraixet y el barranco de la Calderona. Sustento y riqueza de las poblaciones que los rodeaban, no pudieron resistir la proximidad de la gran ciudad y los cambios socio-económicos que en su entorno se empezaron a producir a partir de los años sesenta del siglo XX.

Los recuerdos en la memoria de los más mayores se van borrando. Las generaciones jóvenes tan solo perciben en el paisaje algunos restos que no comprenden. Sirva este artículo para, al menos, en el papel, rememorarlos.

\section{REFERENCIAS}

Anonimo (1887): Crisis arrocera. Actas y dictámenes de la Comisión creada por real Decreto de 20 de Julio de 1886 para estudiar la situación del cultivo y producción de arroz en las provincias de Levante, su coste de producción, las causas de la crisis que atraviesa y los remedios que podrían imponerse para conjurarla. Madrid. Establecimiento Tipográfico "Sucesores de Rivadeneyra" Impresores de la Real Casa. Anonimo (1926): Como se cultiva el arroz. Cámara Oficial Agrícola de la Provincia de Valencia. Valencia. 
Bjornlund, V. y Bjornlund, H. (2019): Understanding agricultural water management in a historical context using a socioeconomic and biophysical framework. Agricultural Water Management, 213, 454-467.

Calatayud, S., Mateu, E. (1999): El uso del agua en el cultivo del arroz en el País Valenciano (siglo XIX). E, El agua en los sistemas agrarios. Una perspectiva histórica. Edición a cargo de Garrabou, R. y Naredo, J.M Fundación Argentaria.

Camarasa, A.M. (1991): Génesis de crecidas en pequeñas cuencas semiáridas, Barranc de Carraixet y Rambla del Poyo. Geografía física. Universitat de València.

Carmona, P. (1990): La formació de la plana al luvial de València. Valencia, Universidad de Valencia.

Carrasco, Jose m. (1952): Compendio arrocero. Valencia. Federación Sindical de Agricultores arroceros de España. Editorial Guerri S.A. 447 ágs

Cavanlles, A.J. (1795-1797): Observaciones sobre la historia natural, geografía, agricultura, población y frutos del reino de Valencia, Tomos I y II. Madrid: Imprenta Real.

D'Amaro (2014): Instituciones y conflicto en el franquismo. La resistencia de los regantes a la integración en los sindicatos (1944-1957) En Sanchis-Ibor, C.; Palau-Salvador, G., Mangue Alferez,I y Martinez-Sanmartín, L.P. (eds): Irrigatión, Society, Landscape. Tribute to Thomas F. Glick. Valencia. Universidad Politécnica de Valencia. Págs. 619-633.

García, E (1929): El arroz, cultivo y comercio. Espasa-Calpe S.A.

Gaviria, M., Marco, J. (1974): La Autopista como agresión. Revista TRIUNFO.

Gimenez, P (2007): Las transformaciones del paisaje valenciano en el siglo XVIII. Institució Alfons el Magnànim-Diputació de València. 460 págs.

Glick, T.F. (1988): Regadío y sociedad en la Valencia Medieval. Valencia. Del Cenia al Segura. Reedición (2003) de la Biblioteca Valenciana. Generalitat Valenciana. 413 págs.

Madoz, P. (1848): Diccionario Geográfico-estadístico-histórico de España y sus posesiones de Ultramar. Madrid. Imprenta del DGEH de Don Pascual Madoz.

Mateu, E. (1987): Arroz y Paludismo. Edicions Alfons el Magnanim. Institució Valenciana d'Estudis i Investigació. Valencia. 192 págs.

Ministerio de Agricultura (1952): Mapa Agronómico Nacional. Comarca de Sueca, 2 tomos. Ministerio de Agricultura. Madrid.

Rodríguez, M. (1906): El arroz. Ed. De Bailly-Bulleire e Hijos. Madrid.

Rodrigo Pertagás, J. (1922): Ensayo sobre topografía preurbana de Valencia. Madrid. Revista de Archivos, Bibliotecas y Museos.

Roselló, V.M. y Panareda, J.M. (2003): Diccionari de geografia física. Barcelona, Termcat, Centre de Terminologia, 414 págs.

Sales, V. (1986): El regadío en la demarcación de la Real Acequia de Moncada. Tesis de licenciatura. Universitat de València.

Sales, V. (1988): La cuestión del extremal en el regadío de la Real Acequia de Moncada. Cuadernos de geografía. 44, 221-234. 
Sales, V. y Urzainqui, S. (2011): sobre una visura de la Séquia de Moncada en el segle XVI (1576). Actes del III Congrés d'Estudis de l'Horta Nord, Vol I. València. Universitat Politècnica. Págs 97-118.

Sales, V. (2015): Las ampliaciones modernas en los regadíos históricos. Jovedat y Extremal de la Real Acequia de Moncada. Tesis doctoral. Director Guillermo Palau Salvador. UPV.

Sanchis, M. C. (1978): Dos mutaciones paisajísticas ligadas al arrozal en la antigua gobernación de San Felipe (Xàtiva). Cuadernos de Geografía. 22, 59-72.

Segura, F., Pardo, J.E. y Sanjaume, E. (1996): Evolución cuaternaria de la antigua albufera existente entre Puçol y Alboraia. Cuadernos de geografía. 59, 63-86.

Swyngedouw, E. (2009): The political economy and political ecology of the hydro-social cycle. Journal of Contemporary Water Research Eु Education 142, 56-60. doi:10.1111/j.1936-704X.2009.00054.x

Swyngedouw, E. (1999): Modernity and hybridity: Nature, regeneracionismo, and the production of the Spanish waterscape, 1890-1930. Annals of the Association of American Geographers 89, 443465. doi:10.1111/0004-5608.00157

Teixidor, M.J. (1980): Una lectura de la expansión urbana de Valencia: el modelo de crecimiento axial. En: Saitabi, 1980, No. 30: 199-213.

Zaragozà, M. (1982): El cultivo tradicional de l'arròs a Silla. Ajuntament de Silla, Universitat de València.

Cómo citar este artículo:

Sales, V., Ortega-Reig, M.V., Palau Salvador, G. (2019). Gestión, transformación y desaparición del arrozal al norte de la ciudad de València (1767-1976). Cuadernos de Geografía, 102, 87-106.

https://doi.org/10.7203/CGUV.102.14596

\section{(c) $(1) \Theta \Theta$}

Este obra está bajo una licencia de Creative Commons Reconocimiento-NoComercial-SinObraDerivada 4.0 Internacional. 
